\title{
Catheter-induced urethral injury and tubularized urethral plate urethroplasty in such iatrogenic hypospadias
}

\author{
Ami Lal Bhat ${ }^{1,2^{*}} \mathbb{0}$, M. Bhat ${ }^{1}$, N. Khandelwal ${ }^{2}$, A. Bhat ${ }^{3}$ and T. Singh ${ }^{1}$
}

\begin{abstract}
Background: Catheter-induced urethral erosion can involve meatus, glans and any extent of penile shaft. These injuries cause a lot of psychological, social and sexual trauma to the patient. Though the use of condom drainage system can render this spinal cord injury patient effectively dry, but can lead to penile or urethral complications. Many of these patients are kept on indwelling catheter. Long duration catheterization, poor catheter care in such paraplegic patients and other morbid patients may lead to urethral erosions. We conducted a prospective study of catheterinduced urethral injury from July 2014 to February 2016 in our tertiary care centre. The demographics, past history of illness, catheter material, and duration of catheterization, securing of catheter, local examination findings and associated comorbidities were recorded. Factors leading to urethral erosion were evaluated. And patients, who were fit and were willing for surgery, underwent tubularized urethral plate urethroplasty after 4-6-week supra-pubic diversion. The objective of the study was to evaluate factors of urethral erosion, and the results tubularized urethral plate urethroplasty in iatrogenic hypospadias.
\end{abstract}

Results: We had twelve patients of catheter associated urethral injury in the study period. Age of the patients varied from 34 to 95 years with a mean of 61.25 years. Duration of catheterization ranged from 6 to 24 months with a mean duration 10.9 months. Catheters used were silicon coated, not secured to abdomen and had comorbid condition of neurological or cardiac origin in all patients. Long duration of catheter, poor quality of catheter and poor catheter care such moribund with poor body resistance patients were the main causative factor for urethral erosion. Urethral injuries varied from erosion of distal $2 \mathrm{~cm}$ to entire ventral urethra till penoscrotal junction with or without penile torque. Six of these patients underwent tubularized urethral plate urethroplasty with good cosmetic and functional postoperative outcome.

Conclusion: Patients of spinal cord injury, patients with comorbid condition like diabetes mellitus and ischaemic heart disease, poor catheter care and long duration catheterization are likely to have severe urethral injury. Extent of injury may vary from meatal erosion to erosion of entire ventral urethra till penoscrotal junction leading to iatrogenic hypospadias. These patients either may be put on clean intermittent catheterization or supra-pubic catheterization. Results of tubularized urethral plate urethroplasty in such iatrogenic hypospadias are very good.

Keywords: latrogenic hypospadias, Urethra erosion, Indwelling catheter complications, Urethral reconstruction, Neurogenic bladder

\footnotetext{
*Correspondence: amilalbhat@rediffmail.com; bhatamilal@gmail.com

${ }^{2}$ Department of Urology, S.P. Medical College, C-15 Sadul Ganj, Bikaner,

Rajasthan 334003, India

Full list of author information is available at the end of the article
}

\section{Background}

Urethral catheter is one of the most commonly used tools in the armamentarium of a Urologist but is not free from complications. The complications are mechanical-bladder and peritoneal perforation $[1,2]$, infectious-cystitis, 
prostatitis, epididymitis, urethritis and periurethral abscess [3, 4], calculi and encrustations [5, 6], and complications of the catheter-knotting [7] and fracture [8], stricture formation and urethral damage $[9,10]$, malignancy associated with catheters [11]. Urethral erosion because of catheter injury may involve meatus, glans and any extent of penile shaft. Such catheter-induced urethral injuries are uncommon, less than fifty cases reported [9, $10,12,13]$. These injuries may lead to a lot of psychological, social and sexual trauma to the patient. The use of condom drainage system in such cases can render a male spinal cord injury patient dry, but can lead to penile or urethral complications in about $15-30 \%$ of patients [2]. Other complications range from allergic reactions and local defects in the skin, penile cleavage, to gangrene and partial amputation of the penis $[3,4]$. These complications can be prevented with proper catheter care and timely change of catheter, but if such complications occur, should be identified early and treated promptly. We came across 12 such patients in last 2 years in our department and in a group of tertiary referred patients with other neurological dysfunction. The extent of injury was variable with most minor abnormality being that of a ventral meatal hypospadias, to the most major of complete penoscrotal cleavage. We studied the varied degrees of indwelling catheter-induced urethral erosion, risk factors and outcome of reconstructive surgery. The objective of the study was to evaluate factors of urethral erosion and the results tubularized urethral plate urethroplasty in iatrogenic hypospadias.

\section{Methods}

We conducted a prospective study of catheter-induced urethral injury from July 2014 to February 2016 in our tertiary care centre. The demographics, past history of illness, catheter material, and duration of catheterization, securing of catheter, local examination findings and associated co-morbidities were recorded. Factors leading to urethral erosion were evaluated. Patients, who were fit and were willing for surgery, underwent tubularized urethral plate urethroplasty after 4-6-week supra-pubic diversion. Details of intra-operative findings, procedure, postoperative course and complications were noted.

Technique: After injecting 1:100,000 solution of adrenaline inverted $U$ shape incision was given encircling the laid open urethra then circumferential circumcoronal (Fig. 1a, b) Laid open urethra with spongiosum was mobilized proximally up to penoscrotal junction and distally into glans up to meatus (Fig. 1c, d) which corrected the torsion also. Urethral margins were freshened. Urethral mucosa was tubularized, and spongioplasty was done (Fig. 1e). Meatal reconstruction and glanuloplasty were done (Fig. 1f, g) Skin closure was adjusting the skin flap if there is torque (Fig. 1h). Patients were followed at 1 month, 3 months and 6 months with uroflowmetry and retrograde urethrogram at 6 months. Patients with neurogenic bladder were put on clean intermittent catheterization postoperatively.

\section{Results}

During the study period, twelve patients of catheter associated urethral injury were found. Mean age of patients was 61.25 years (range 34-95 years). Mean duration of catheterization, before injury was detected, was 10.9 months (range 6-24 months). Catheters were silicon coated but were not secured to abdomen in any of these.

All the patients had some kind of neurological or cardiovascular comorbidities. Four patients were on indwelling periurethral catheter following traumatic spinal cord injury. Urethral injuries varied from meatal erosion to erosion of entire ventral urethra till penoscrotal junction with or without penile torque (Table 1). Out of twelve patients, one patient had meatal erosion, five had glanular erosion, one had erosion till distal penis, three had erosion till mid penis and two have erosion till penoscrotal junction. Four of the patients had anticlockwise torsion ranging from $80^{\circ}$ to $100^{\circ}$ (Fig. 2). Long duration of catheter, poor quality of catheter and catheter care in moribund with poor body resistance were the main causative factors for urethral erosion.

Six of these patients underwent tubularized urethral plate urethroplasty with good cosmetic and functional postoperative outcome. Urethrogram at and 3 months revealed normal caliber urethra. Four of the patients' spinal cord injuries were not able to void, so they were put on the clean intermittent catheterization after surgery. Two of the diabetic patients had very poor flow rates but were able to empty the bladder. One of them had meatal narrowing which responded to meatal dilatation.

\section{Discussion}

Indwelling urethral catheter-associated urethral erosion is a rare complication. Urethral erosion can be partial thickness or full-thickness involving meatus, glans and penile shaft. We had such twelve cases of urethral erosion, and $50 \%$ (five patients with spinal pathology and one with diabetes and coronary artery) of them had undergone surgical intervention. Most of the cases reported in the literature are of spinal cord injury, but in our series 4 cases were of spinal cord injury, 1 with cauda equina syndrome, 2 cases of diabetes and cerebrovascular accident, 3 with diabetes and cardiovascular disease and one with diabetes and benign hyperplasia of prostate.

Mean duration of catheterization, before injury was detected, was 10.9 months (range 6-24 months) with most of the patients and their attendants often unaware 

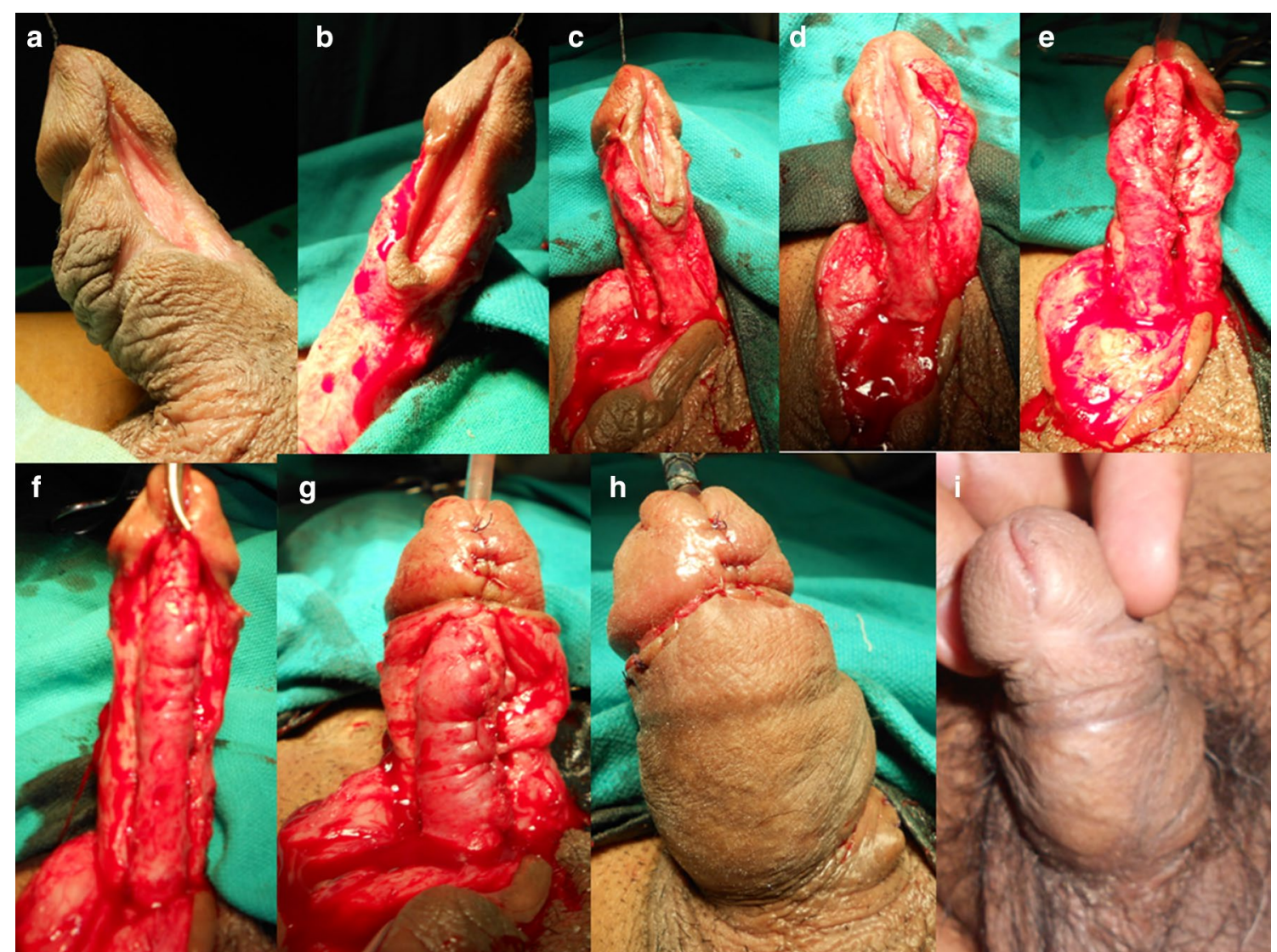

Fig. 1 Steps of tubularization urethral plate urethroplasty in iatrogenic hypospadias. a Mid-penile iatrogenic hypospadias, b penile de-gloving done, $\mathbf{c}, \mathbf{d}$ mobilization of spongiosum and laid open urethra, e tubularization of urethral plate, $\mathbf{f}$ spongioplasty, $\mathbf{g}$ glanuloplasty, $\mathbf{h}$ skin closure, $\mathbf{i}$ postoperative at 6 months

of the damage but the injury came to light when urethral catheterization became a problem for a variety of reasons. Distal urethral erosion was noticed in one of the patient with catheter in situ presented to us as vesical calculus and bladder irritation symptoms. Majority of these patients have underlying neurological dysfunction $[10,15,16]$. Impaired penile sensation is not a pre-requisite for this condition but may aggravate the injury [14]. In the study, five patients had one or more comorbidities. Additionally two patients had coronary artery disease, and two had diabetes mellitus. These are important factors in erosion of urethra with indwelling catheter. Additionally, the presence of periurethral infection is another contributing factor. Fixing the catheter on thigh with leg bag will not allow free movement of catheter, so the indwelling catheter acts as a bowstring when the patients have erections and may be an important factor in urethral erosion. Securing the catheter abdominal wall prevents pressure on the ventral surface which helps in prevention ventral urethral erosion. This is more common because of weak ventral support of corpus spongiosum to urethra and strong support of thick corpora cavernosum on dorsal aspect. Of course, discarding indwelling urethral catheter is the best way to prevent erosion of urethra. Intermittent catheterization is preferable to indwelling urinary catheter drainage. Supra-pubic cystostomy for the patients requiring the long-term catheterization will help in preventing catheter-induced erosion of urethra.

Mary et al. reported role of catheter material and securing the catheter in urethral trophic ulcers and use of soft silicone catheters and securing the catheter on abdominal wall reduces the incidence of urethral complications. Indwelling catheter-associated urethral erosions have been proposed to cause trophic ulcers due to neurogenic and vasculogenic deficiency [12]. In the study, silicon-coated catheters had been used instead of soft silicon catheter and catheters were not secured, thus increasing the chances of urethral erosion. Four of the patients had anticlockwise torque; this could be because of the fixation of spongiosum to corpora to one side on the direction of catheter traction (Fig. 2). 
Table 1 Showing salient features

\begin{tabular}{|c|c|c|c|c|c|c|c|c|}
\hline S. no. & Age (years) & $\begin{array}{l}\text { Duration } \\
\text { of catheterization } \\
\text { (months) }\end{array}$ & $\begin{array}{l}\text { Catheter } \\
\text { secured } \\
\text { or not }\end{array}$ & $\begin{array}{l}\text { Referred } \\
\text { from department }\end{array}$ & Co-morbidities & Nature of injury & $\begin{array}{l}\text { Reconstruction } \\
\text { urethroplasty }\end{array}$ & SPC \\
\hline 1. & 55 & 6 & Not & Neurology & $\begin{array}{l}\text { Cauda equina syn- } \\
\text { drome, coronary } \\
\text { artery disease }\end{array}$ & $\begin{array}{l}\text { Ventral urethral ero- } \\
\text { sion till penoscrotal } \\
\text { junction with } 110^{\circ} \\
\text { anticlockwise } \\
\text { penile torque }\end{array}$ & Yes & Yes \\
\hline 2. & 65 & 8 & Not & Neurology & $\begin{array}{l}\text { Diabetes, hyperten- } \\
\text { sion, stroke }\end{array}$ & $\begin{array}{l}\text { Ventral urethral ero- } \\
\text { sion till mid penis } \\
\text { with } 90^{\circ} \text { clockwise } \\
\text { penile torque }\end{array}$ & No & Yes \\
\hline 3. & 45 & 12 & Not & $\begin{array}{l}\text { Physiotherapy and } \\
\text { rehabilitation }\end{array}$ & $\begin{array}{l}\text { Traumatic quadri- } \\
\text { plegia }\end{array}$ & $\begin{array}{l}\text { Ventral urethral ero- } \\
\text { sion till penoscrotal } \\
\text { junction with } 80^{\circ} \\
\text { anticlockwise } \\
\text { penile torque }\end{array}$ & Yes & Yes \\
\hline 4. & 34 & 7 & Not & Neurosurgery & Traumatic paraplegia & $\begin{array}{l}\text { Glanular erosion with } \\
\text { urethrocutaneous } \\
\text { fistula at proximal } \\
\text { penile urethra level }\end{array}$ & Yes & Yes \\
\hline 5. & 95 & 6 & Not & Self & $\begin{array}{l}\text { Hypertension, coro- } \\
\text { nary artery disease }\end{array}$ & Glanular erosion & No & Yes \\
\hline 6. & 42 & 14 & Not & Orthopedics & Traumatic paraplegia & Glanular erosion & No & Yes \\
\hline 7. & 92 & 24 & Not & Medicine & $\begin{array}{l}\text { Diabetes, hyperten- } \\
\text { sion, coronary } \\
\text { artery disease }\end{array}$ & $\begin{array}{l}\text { Ventral urethral ero- } \\
\text { sion till mid penis } \\
\text { with } 90^{\circ} \text { anticlock- } \\
\text { wise penile torque }\end{array}$ & Yes & Yes \\
\hline 8. & 63 & 11 & Not & Self & $\begin{array}{l}\text { Diabetes, benign } \\
\text { prostatic hyper- } \\
\text { plasia }\end{array}$ & $\begin{array}{l}\text { Ventral urethral ero- } \\
\text { sion till Distal penis }\end{array}$ & Yes & Yes \\
\hline 9. & 71 & 7 & Not & Medicine & $\begin{array}{l}\text { CAD, depression (on } \\
\text { treatment) }\end{array}$ & $\begin{array}{l}\text { Glanular erosion till } \\
\text { corona }\end{array}$ & No & Yes \\
\hline 10. & 84 & 12 & Not & Medicine & $\begin{array}{l}\text { CVA with neurogenic } \\
\text { Bladder }\end{array}$ & Meatal erosion & No & Yes \\
\hline 11. & 34 & 9 & Not & Orthopedics & Traumatic paraplegia & $\begin{array}{l}\text { Ventral urethral ero- } \\
\text { sion till mid penis }\end{array}$ & Yes & Yes \\
\hline 12. & 55 & 15 & Not & Medicine & $\begin{array}{l}\text { Hypertension, coro- } \\
\text { nary artery disease }\end{array}$ & Glanular erosion & No & Yes \\
\hline
\end{tabular}

Elderly patients with comorbidities are poor candidates for surgical reconstruction of urethra. Secrest et al. studied 17 patients with neurogenic bladder who underwent urethral reconstruction. Of those, 11 with spinal cord injury required reoperation and all eventually required urinary diversion [15]. Andrews et al. repaired six cases out of sixteen cases of iatrogenic hypospadias. They reported successful outcome in all these patients without any complication [16].

In our study, age, diabetes, coronary artery disease, neurological diseases like cerebrovascular accidents and cauda equina syndrome, spinal cord injury, etc., were risk factors for urethral erosion following long-term indwelling catheterization.

We reconstructed six cases with satisfactory outcome. Urethroplasty is needed to do clean intermittent catheterization in cases of lower motor neuron bladder. The results from repair were very gratifying as the penis returned to its normal appearance. Tubularization of laid open urethra is feasible in most of the cases, but if there is extensive scarring and the urethral plate was insufficient for primary closure, then a substitution urethroplasty is recommended. A dartos or tunica vaginalis flap can be developed and placed over to support the neourethra. Graft tissue is harvested depending on tissue availability either excess penile skin, non-hair bearing skin and Buccal mucosa. Inner preputial flap urethroplasty can be done if prepuce skin is available. Urethral erosion is a preventable complication of indwelling catheter. Patients and their attendants should be counseled and educated about the complications of catheterization and about their prevention. Patients with neurogenic bladders could be best put on self-calibration. Patients requiring long-term catheterization should be counseled for supra-pubic diversion 


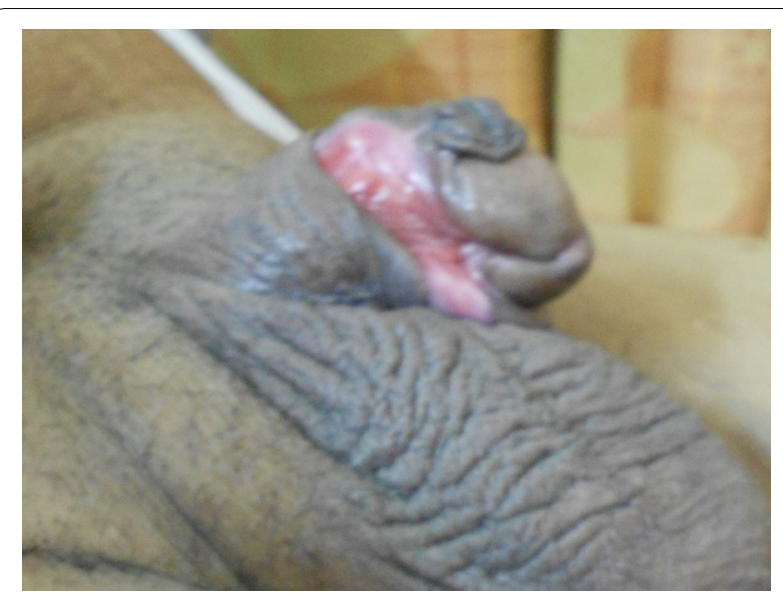

Fig. 2 Showing the erosion of urethra with $90^{\circ}$ anticlockwise torsion

of urine [16]. Recurrence of stricture is not a problem in the spinal cord patients because these patients are put on clean intermittent catheterization. Four of patients put on CIC did not have any recurrence, but one patient with spontaneous voiding has meatal stenosis. Limitation of the study is of 12 patients only, so statistically significant conclusions cannot be derived. Since our study duration is short, longer follow-ups are required to ascertain longterm complications of the reconstructive surgery such as stricture, diverticulum, urethrocutaneous fistula.

\section{Conclusion}

Neglected patients of spinal cord injury/pathology, comorbid condition like diabetes mellitus and ischaemic heart disease, poor catheter care and long duration catheterization in these patients may lead to severe urethral injury. Extent of injury may vary from meatal erosion to erosion of entire ventral urethra till penoscrotal junction leading to iatrogenic hypospadias. Correct securing the catheter to abdominal wall with tape and ensuring the drainage system supported without traction is essential to prevent urethral erosion. Such patients requiring long duration catheterization may either be put on clean intermittent catheterization or supra-pubic diversion. Results of tubularized urethral plate urethroplasty in such iatrogenic hypospadias are very good. Recurrence of stricture is not a problem in the spinal cord patients because these patients are put on clean intermittent catheterization.

\section{Acknowledgements}

Nil.

\section{Authors' contributions}

ALB and MB contributed to concepts, design of work, literature search, data acquisition, data analysis, manuscript preparation, manuscript editing, and manuscript review. NK and AB were involved in literature search, data acquisition, data analysis, manuscript preparation, manuscript editing, and manuscript review. TS contributed to literature search, data acquisition, data analysis, manuscript preparation, manuscript editing, and manuscript review. All authors read and approved the final manuscript.

Funding

Not applicable.

Availability of data and materials

Yes, the data will be available if required.

Competing interests

The authors declare that they have no competing interests.

Consent for publication

Yes, we give permission to publish the article in the esteemed journal.

\section{Ethics approval and consent to participate}

Yes, Institutional Ethical Committee [DCG(I) Registration ECR/27/SP/INS/Raj/2013

Dated 8.3. 2014]. Since it was a retroscopic review, consent was not required.

\section{Author details}

${ }^{1}$ Department of Urology, Dr. S. N. Medical College Jodhpur, Jodhpur, Rajasthan 334003, India. ${ }^{2}$ Department of Urology, S.P. Medical College, C-15 Sadul Ganj, Bikaner, Rajasthan 334003, India. ${ }^{3}$ Department of Surgery, S.P. Medical College, Bikaner, Rajasthan 334003, India.

Received: 7 November 2019 Accepted: 5 February 2020

Published online: 02 June 2020

\section{References}

1. Avmerich-Real J, Morote-Robles J, de-Torres-Mateos JA, Malet-Carrerras JM (1985) Intraperitoneal bladder perforation by a permanent bladder catheter. Acta Urol Esp 9:277-278

2. Merguerian PA (1985) Peritonitis and abdominal free air due to perforation associated with indwelling catheter drainage. J Urol 134:747

3. Elhilai MM, Hassouna M, Abdel-Hakin A, Teijeira J (1986) Urethral Stricture following cardiovascular surgery: the role of urethral ischaemia. J Urol 135:275-277

4. Weiss BD (1984) Chronic indwelling catheterization. Am Fam Physician 30:161-166

5. DeVivo MJ, Fine PR, Cutter GR, Maetz HM (1985) The risk of bladder calculi in patients with spinal injuries. Arch Int Med 145:428-430

6. Huskin D, Hickey DS, Kennedy AP (1983) Catheter encrustation by struvite. B J Urol 55:304-305

7. Pearson-Shaver AL, Anderson MH (1992) Urethral catheter knots. Paediatrics 85:852-854

8. Harland RW, DeGroot DL, DeWire DM (1992) The 'Fractured Foley'_an unusual complication of chronic indwelling catheterisation. J Am Geriatr Soc 40:827-828

9. Barnes-Snow E, Luchi RJ, Doig R (1985) Penile laceration from a Foley catheter. J Am Geriatr Soc 33:712-714

10. Larsen T, Hansen BJ (1989) Longitudinal cleavage of the penis, a rare complication seen in paraplegic patients. Int Urol Nephrol 21:313-316

11. Goble NM, Clark TJ, Teasdale C (1990) Signet ring adenocarcinoma of the bladder secondary to long term catheterisation. Urology 35:279-281

12. Bell MA (2010) Severe indwelling urinary catheter-associated urethral erosion in four elderly men. Ostomy Wound Manag 56:36-39

13. CipaTatum J, Kelly Signs M, Afsari K (2011) Urethral erosion: a case for prevention. J Wound Ostomy Cont Nurs 38:5813

14. Bycroft J, Hamid R, Shah PJ (2003) Penile erosion in spinal card injury_an important lesson. Spinal Cord 4:643-644

15. Secrest CL, Madjar S, Sharma AK, Covington-Nichols C (2003) Urethral reconstruction in spinal cord injury patients. J Urol 170:1217

16. Andrews HO, Nauth-Misir R, Shah PJR (1998) latrogenic hypospadias-a preventable injury? Spinal Cord 36:177-180

\section{Publisher's Note}

Springer Nature remains neutral with regard to jurisdictional claims in published maps and institutional affiliations. 